\title{
Extramedullary plasmacytoma of Paranasal sinus: A rare case report
}

\author{
Harendra Kumar Gautam ${ }^{*}$, Shalini Tripathi ${ }^{2}$ \\ ${ }^{1}$ Associate Professor, ${ }^{2}$ Junior Resident, Dept. of ENT, Ganesh Shankar Vidyarthi Memorial Medical College, Kanpur, Uttar \\ Pradesh, India
}

*Corresponding Author: Harendra Kumar Gautam

Email: harendragautam34@yahoo.in

\begin{abstract}
We report an extremely aggressive case of extramedullary plasmacytoma of the right maxillary sinus without any known metastasis. A 45 year old male presented to ENT Department with chief complaints of recurrent Right sided nasal mass and nasal obstruction with recurrent episodes of cold for 3 years. Patient also had decreased sense of smell. Before presenting to us, he underwent two previous surgeries for the same complaint elsewhere in the year 2015 and 2017. Patient was a known case of Hypertension for 3 years and took treatment, was immunocompetent. Subsequent investigations including CT scan of Paranasal sinuses and peri-operative findings revealed a sinonasal mass involving right maxillary antrum with erosion of all the walls of maxillary antrum. Soft tissue mass lesion also extending into retro-zygomatic space, nasal cavity and buccal space. The nasal cavity mass lesion extending posteriorly to occupy whole of nasopharynx and overhanging into oropharynx. The patient was treated surgically by Cald well Luc's approach and mass removed. HPE reports suggestive of tumour comprising of plasma cells with varying degree of maturation and atypia, nucleus- characteristic "clock face chromatin"pattern seen. Abundant basophilic cytoplasm. On IHC- CD 138 weak positive. Suggestive of Extramedullary plasmacytoma. Patient underwent 20 cycles of radiotherapy. Patient is on follow up since then and is asymptomatic.
\end{abstract}

Keywords: Extramedullary plasmacytoma, PNS and HPE.

\section{Introduction}

Extramedullary plasmacytomas (EMPs) are solitary tumours consisting of neoplastic plasma in which cell proliferation occurring in locations other than bone. It typically arises in submucosal soft tissues of the upper respiratory tract and it is destructive with a tendency to local recurrence. ${ }^{1,2}$ The disease is more common in the male sex, during the fifth and sixth decades of life. They represent up to $4 \%$ of non-epithelial lesions of upper respiratory tract. The optimal management of EMP is controversial. Surgery can achieve high rates of local control in certain situations. However, radical excision is often impossible due to the size or the location of the tumour. ${ }^{3}$ However recent studies demonstrate better long term outcomes through a combination of RT and surgical removal. ${ }^{4,5}$ Surgery alone has also been proven highly efficient, provided that negative resection margins are attained. ${ }^{5}$

\section{Case Report}

We report an extremely aggressive case of extramedullary plasmacytoma of the right maxillary sinus without any known metastasis. A 45 year old male, known case of hypertension and immunocompetent, presented to ENT Department with chief complaints of recurrent right sided nasal mass and nasal obstruction with rhinorrhea of 3 years duration. He also had facial swelling which was associated with dull pain and decreased sense of smell. He experienced a loss of appetite and loss of weight. The patient has treatment history of undergoing surgery for similar complaints at other centers in the year 2015 and 2017. The earlier biopsy reports were inconclusive or suggestive of inflammatory polyp.

He was subsequently evaluated at our center with investigations including CT scan of paranasal sinuses. Pre-operative findings revealed a sinonasal mass involving right maxillary antrum with erosion of all the walls of maxillary antrum. Soft tissue mass lesion also extending into retro zygomatic space, nasal cavity and buccal space. The nasal cavity mass extending posteriorly to occupy whole of nasopharynx and overhanging into oropharynx. Intra-orally, right hard palate was pushed inferiorly. (Fig. 1)

The patient underwent excision of mass by Caldwell Luc's approach under GA. Postoperative periods were uneventful. On HPE reports were suggestive of tumour comprising of plasma cells with varying degree of maturation and atypia. Tumour cells are present in sheets. Nucleus shows characteristic "clock face chromatin" pattern with abundant basophilic cytoplasm. On IHC- CD 138 weak positive. Suggestive of Extramedullary plasmacytoma. Patient underwent 20 cycles of radiotherapy. Patient is on follow up since then and is asymptomatic. (Fig. 2,3) 


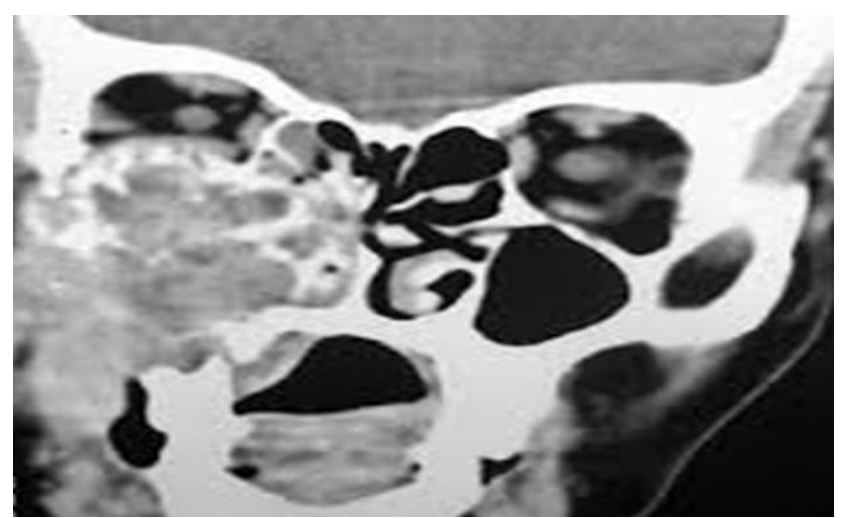

Fig. 1: Preoperative CT finding.

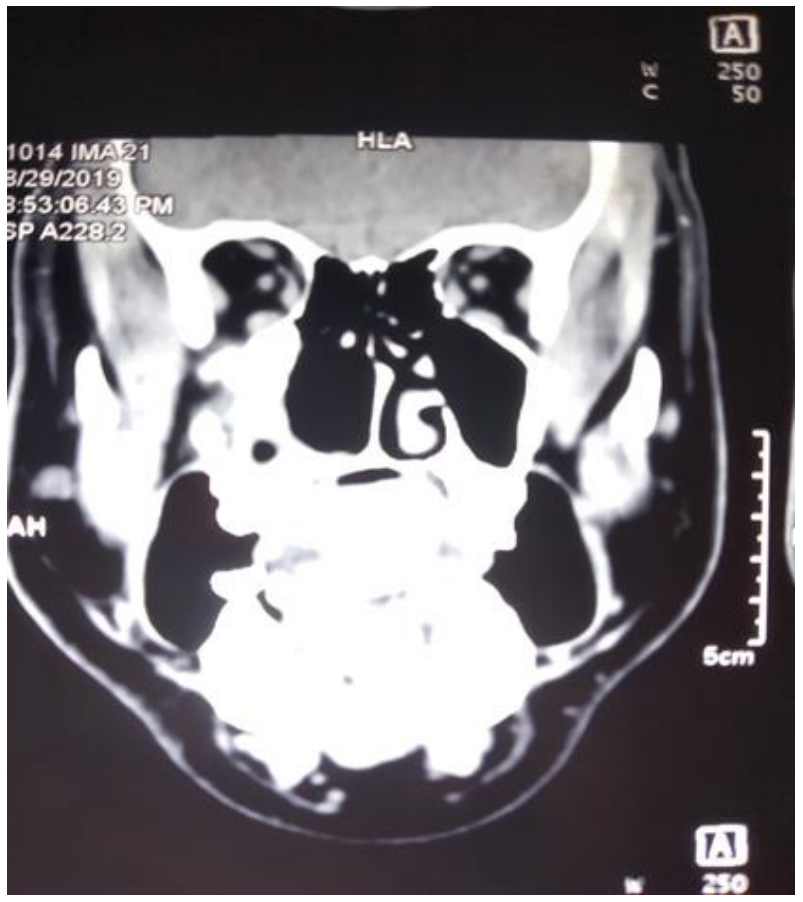

Fig. 2: Post-operative CT finding.

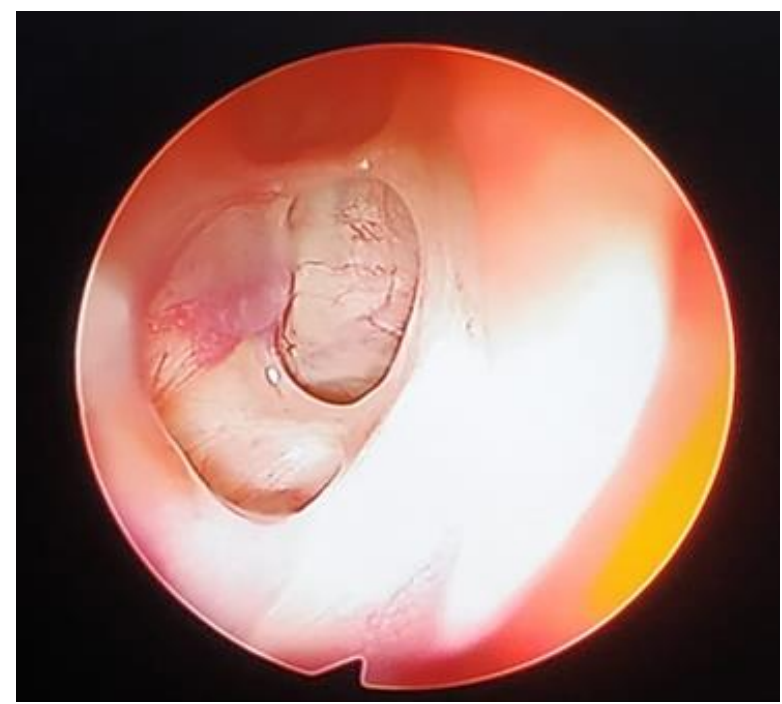

Fig. 3: Post-operative nasal endoscopy.

\section{Discussion}

Extramedullary plasmacytomas (EMPs) are localized plasma cell neoplasms that occur within the soft tissues; by definition they cannot occur within bone. They account for $1-2 \%$ of all plasma cell growths and have a great predilection for the upper respiratory tract, without specific manifestations. Approximately 80-90\% of EMP involve the Mucosa-Associated Lymphoid Tissue (MALT) of the upper airways, 75\% of these involve the nasal and paranasal regions. ${ }^{6}$ Males are more frequently affected during the fifth and sixth decades of life. The clinical presentation is not specific, depending upon tumor location. The most common nasal symptoms, as confirmed by our survey, are progressive nasal obstruction and recurrent epistaxis. ${ }^{7,8}$ Other possible symptoms are swelling, headache, nasal discharge or proptosis. ${ }^{9,10}$ pain usually occurs when there is bone involvement or infection. The tumor displays submucosal growth and the mucosa might be thickened as a result of a chronic inflammation, ${ }^{10}$ profound biopsies should be taken to avoid errors. CT, MRI and a full endoscopic examination are mandatory to determine tumor extension. ${ }^{10,11}$ EMP arising in the right maxillary sinus who was referred for surgical excision and postoperative radiotherapy and briefly review the clinical implications and management of this pathology. ${ }^{10}$

\section{Conclusion}

Based on a thorough review of the medical literature, it may be concluded that these neoplasms are associated with a good prognosis. This case report which describes a rare tumor of the nasal cavity is expected to improve the recognition and referral of this condition by ear, nose and throat (ENT) specialists for multidisciplinary management and long term follow-up.

Radiation therapy achieves excellent loco regional control of EMP with an approximate cure fraction of $50 \%$.Lower recurrence rates have been observed with a combination of surgical excision and radiotherapy as was found in this case.

\section{Source of funding}

None.

\section{Conflict of interest}

None.

\section{References}

1. Wiltshaw E. The natural history of extramedullary plasmacytoma and its relation to solitary myeloma of bone 
and myelomatosis. Med 1976; 55:217-38. [PubMed] [Google Scholar]

2. Kapadia SB, Desai U, Cheng VS. Extramedullary plasmacytoma of the head and neck: a clinicopathologic study of 20 cases. Med 1982;61:317-29.

3. Michalaki VJ, Hall J, Henk JM, Nutting CM, Harrington KJ. Definitive radiotherapy for extramedullary plasmacytomas of the head and neck. Br J Radiol 2003;76:738-41.

4. Alexiou C, Kau RJ, Dietzfelbinger H. Extramedullary plasmacytoma: tumor occurrence and therapeutic concepts. Cancer 1999;85:2305-14

5. Lomeo PE, McDonald JE, Finneman J, Shoreline Extramedullary plasmacytoma of the nasal sinus cavities. Am J Otolaryngol 2007;28(1):50-1.

6. Sik-Chung Ching A, Boom-Kheng Khoo J, Fook-Hin Chong V.CT and MRI imaging of solitary extramedullary plasmacytoma of the nasal tract. Am J Neuroradiol 2002;23:1632-6.

7. Sahin S, Dulundu H, Coskun H. Nasal plasmocytoma. In: proceedings of the XV World Congress ORL, Head Neck Surg 1993;2:486-8.
8. Creach KM, Foote RL, Neben-Wittich MA, Kyle RA. Radiotherapy for extramedullary plasmacytoma of the head and neck. Int J Radiat Oncol Biol Phys 2009;73(3):789-94.

9. Baek BJ, Kim SW, Park H, Park JK, Han KY, Oh CH et al. Extramedullary plasmacytoma arising from the nasal septum. Ear Nose Throat J 2005;84(11):720-2.

10. Ersoy O, Sanlıer T, Yigit O, Halefoglu AM, Ucak S, Altuntas $\mathrm{Y}$ et al. Extramedullary plasmacytoma of the maxillary sinus. Acta Otolaryngol 2004; 124:642-4.

11. Sasaki R, Yasuda K, Abe E, Uchida N, Kawashima M, Uno $\mathrm{T}$, et al. Multi-Institutional Analysis of Solitary Extramedullary Plasmacytoma of the Head and Neck Treated With Curative Radiotherapy. Int J Radiat Oncol Biol Phys 2012;82(2):626-34.

How to cite: Gautam HK, Tripathi S. Extramedullary plasmacytoma of Paranasal sinus: A rare case report. $I P$ J Otorhinolaryngol Allied Sci 2020;3(1):29-31. 